\title{
Fibromyalgia: Where Are We a Decade After the American College of Rheumatology Classification Criteria Were Developed?
}

\author{
Leslie J. Crofford ${ }^{1}$ and Daniel J. Clauw ${ }^{2}$
}

The American College of Rheumatology (ACR) published classification criteria for fibromyalgia (FM) in 1990 (1). These criteria allow investigators around the world to investigate mechanisms of symptom expression in FM with assurance that research subjects share the presence of chronic widespread pain and evidence of altered pain processing, as demonstrated by the presence of tender points. With publication of the classification criteria, the ACR assumed a leadership position in research into basic mechanisms underlying FM symptoms and management of patients with FM. What progress has been made in the decade since the ACR classification criteria were developed?

A strength of the criteria from a research standpoint is that FM patients meeting the ACR classification criteria are at the extreme end of the spectrum of pain and tenderness. As a result, a number of studies have demonstrated important alterations in pain processing in FM. These studies use subjective ratings of experimental pain paradigms as well as objective demonstration of an altered central representation of painful stimuli.

Petzke et al demonstrated that patients with FM had low mechanical and thermal pain thresholds regardless of whether the stimulus was presented in a predictable, ascending manner (as with tender point determinations or dolorimetery) or randomly (2). These data suggest that, compared with healthy individuals, FM patients do not rate pain stimuli higher because of psychological hypervigilance or "expectancy." Staud et al showed that patients with FM exhibit altered temporal summation of pain stimuli administered as a thermal stimulus to skin or as a mechanical stimulus to muscle

${ }^{1}$ Leslie J. Crofford, MD: University of Michigan, Ann Arbor; ${ }^{2}$ Daniel J. Clauw, MD: University of Michigan, Ann Arbor, and Georgetown University, Washington, DC.

Address correspondence and reprint requests to Leslie J. Crofford, MD, Room 5510A, MSRB-I, 1150 West Medical Center Drive, Ann Arbor, MI 48109-0680. E-mail: crofford@umich.edu.

Submitted for publication November 27, 2001; accepted December 5, 2001.
$(3,4)$. The results of these studies suggest a parallel between the human condition of FM and the "wind-up" phenomenon that leads to hyperalgesia and has been extensively studied in animal models (5).

Other data corroborating the veracity of FM patients' descriptions of pain have been collected using paradigms that are not dependent on subjective reports by patients. For example, Lorenz et al demonstrated altered laser-evoked potentials as objective representation of the central nervous system (CNS) response to cutaneous stimulation (6). Patients with FM were shown by Mountz et al and by Cianfrini et al to have reduced thalamic blood flow under resting conditions (a finding observed in other chronic pain states) and altered responses to mechanical pain stimuli $(7,8)$. Finally, Grant et al demonstrated that increased blood flow to brain regions known to receive pain input correlates with the intensity of perceived pain rather than the absolute level of the stimulus (9).

All these data arguably complement the most consistent biologic finding supporting aberrant central pain transmission in FM-the $\sim 3$-fold higher concentrations of substance $\mathrm{P}$ in cerebrospinal fluid (CSF) of FM patients compared with those in the CSF of normal controls (10-13). Taken together, the data on pain processing in FM demonstrate that the central representation of pain correlates with patient reports of pain, and that purely behavioral or psychological factors are not primarily responsible for the pain and tenderness seen in FM.

The ACR classification criteria focus only on pain, however, and disregard other important FM symptoms, including fatigue, cognitive disturbance, sleep disturbance, and psychological distress. If one takes a more general view of FM that includes these symptoms and commonly associated syndromes (e.g., chronic fatigue syndrome, irritable bowel syndrome, and depression), then the ACR criteria fail to capture the essence of the FM syndrome. When research subjects are identified using the ACR criteria, there is greater variability 
in studies of physiologic mechanisms other than pain processing. For example, studies of the hypothalamicpituitary-adrenal (HPA) axis must consider the impact of comorbid conditions (e.g., mood disorders and chronic fatigue syndrome, neither of which is an exclusion to the diagnosis of FM) that might independently alter HPA axis activity. Nevertheless, studies of the HPA axis (14-17) and the sympathetic nervous system (18-22) have demonstrated alterations in most instances. It is plausible that alterations of these stress-response systems identify a population vulnerable to the development of FM. Alternatively, altered neuroendocrine axis activity could cause or occur as a consequence of some FM symptoms. It is likely that these neurobiologic alterations are shared with other poorly understood somatic syndromes and psychiatric disorders that frequently occur concurrently with FM.

In this issue of Arthritis \& Rheumatism, Paiva et al describe an important neuroendocrine disturbance seen in FM patients. This study represents an extension of previous work by this group demonstrating that serum levels of insulin-like growth factor 1 are diminished in a substantial percentage of FM patients, and that treating these individuals with human recombinant growth hormone $(\mathrm{GH})$ leads to improvement of symptoms $(23,24)$. The present study demonstrates that failure of the $\mathrm{GH}$ axis to respond to an exercise stress is attributable to increased levels of somatostatin. Somatostatin tone is critically important to physiologic alteration in $\mathrm{GH}$ secretion, both acutely (e.g., exercise) and chronically (e.g., aging, obesity). Although the study by Paiva et al does not determine the reason for increased somatostatin tone, all of the possibilities suggested by the authors include regulatory mechanisms localized to the CNS and revolving around an altered physiologic response to stress. Thus, the results of this study provide additional evidence that central mechanisms are involved in the pathophysiology of the FM syndrome.

In addition to neurobiologic mechanisms, behavioral factors play a role in symptom expression in many FM patients. A typical pattern is that as a result of pain and other symptoms of FM, individuals begin to function less well in their various roles. They may have difficulties with spouses, children, and work inside or outside the home, which exacerbate symptoms and lead to maladaptive illness behaviors. Such behaviors include isolation, cessation of pleasurable activities, and reductions in activity and exercise. In the worst cases, patients become involved with disability and compensation systems, which almost ensures that they will not improve (25).

The complex interaction of biologic and behav- ioral mechanisms is not, however, unique to FM. Nonbiologic factors play a prominent role in symptom expression in all rheumatic diseases. In fact, in conditions such as rheumatoid arthritis and osteoarthritis (OA), nonbiologic factors such as level of formal education, coping strategies, and socioeconomic variables account for more of the variance in pain reporting and disability than do biologic factors, such as joint space width or erythrocyte sedimentation rate $(25,26)$. Why, then, should we be surprised that nonbiologic factors play a significant role in FM?

Nevertheless, many rheumatologists express enormous frustration aimed specifically at FM patients or the FM "construct." The most simplistic reason for this frustration may be psychological distress on the part of patients, physicians, or both. Patients with FM display higher average levels of distress than do individuals with other rheumatic disorders (27). Previous unsatisfactory interactions with the health care system may increase the likelihood of an adversarial relationship between patient and physician. Distress on the part of physicians is likely, because mechanisms underlying FM symptoms are poorly understood and are outside the realm of mechanisms traditionally studied by rheumatologists (e.g., immunology, inflammation, connective tissue biology). In addition, current pharmacologic therapies are often ineffective, nonpharmacologic therapies require time to implement, and dealing with contentious issues surrounding FM such as disability compensation or litigation is frustrating and counterproductive.

Population-based studies have demonstrated that chronic pain and fatigue syndromes affect huge numbers of individuals; the results are similar regardless of where the studies are performed or what labels are used to identify these individuals (28). It has been suggested that our specialty should exclude treatment of FM patients for the stated reason that there are not enough rheumatologists to treat the diseases we are uniquely qualified to manage. However, musculoskeletal pain is properly evaluated by rheumatologists, using our specialized knowledge to facilitate the correct diagnosis and institute a treatment plan. What is, perhaps, even more germane is the fact that many of our patients with inflammatory arthritides, connective tissue diseases, $\mathrm{OA}$, and regional soft tissue disorders also manifest symptoms of FM. Studies have demonstrated that $\sim 20 \%$ of individuals with nearly any type of rheumatic disease will meet ACR criteria for FM (29). An even higher percentage will have some elements of pain or other somatic symptoms not explained by immune activation 
or tissue damage or will manifest behaviors that play a prominent role in symptom expression.

Rheumatologists have established a leadership position in research on the mechanisms underlying FM symptoms and the most appropriate treatments for FM patients. That position can be used to educate patients and primary care physicians and dictate how this disorder is best managed. Even if a rheumatologist is required to make the initial diagnosis of FM, treatment can be implemented effectively by primary care physicians. Abandoning our leadership position is not likely to further basic research on the mechanisms underlying FM symptoms, decrease the number of individuals with chronic widespread musculoskeletal pain, or improve management of these patients.

\section{REFERENCES}

1. Wolfe F, Smythe HA, Yunus MB, Bennett RM, Bombardier C, Goldenberg DL, et al. The American College of Rheumatology 1990 criteria for the classification of fibromyalgia: report of the multicenter criteria committee. Arthritis Rheum 1990;33:160-72.

2. Petzke F, Clauw DJ, Khine A, Gracely RH. Increased pain sensitivity in fibromyalgia: effect of two types of stimuli and ascending versus random modes of presentation [abstract]. Arthritis Rheum 2000;43 Suppl 9:S173.

3. Staud R, Vierck CJ, Cannon RL, Mauderli AP, Price DD. Abnormal sensitization and temporal summation of second pain (wind-up) in patients with fibromyalgia syndrome. Pain 2001;91: $165-75$.

4. Staud R, Carl KE, Vierck CJ, Price DD, Robinson ME, Cannon RL, et al. Repetitive muscle stimuli result in enhanced wind-up of fibromyalgia patients [abstract]. Arthritis Rheum 2001;44 Suppl 9:S395.

5. Price DD. Psychological and neural mechanisms of the affective dimension of pain. Science 2000;288:1769-72.

6. Lorenz J, Grasedyck K, Bromm B. Middle and long latency somatosensory evoked potentials after painful laser stimulation in patients with fibromyalgia syndrome. Electroencephalogr Clin Neurophysiol 1996;100:165-8.

7. Mountz JM, Bradley LA, Modell JG, Alexander RW, TrianaAlexander M, Aaron LA, et al. Fibromyalgia in women: abnormalities of regional cerebral blood flow in the thalamus and the caudate nucleus are associated with low pain threshold levels. Arthritis Rheum 1995;38:936-8.

8. Cianfrini LR, McKendree-Smith NL, Bradley LA, Alarcon GS, Deutsch G, Sotolongo A, et al. Pain sensitivity and bilateral activation of brain structures during pressure stimulation of patients with fibromyalgia (FM) is not mediated by major depression (DEP) [abstract]. Arthritis Rheum 2001;44 Suppl 9:S395.

9. Grant MAB, Farrell MJ, Kumar R, Clauw DJ, Cracely RH. FMRI evaluation of pain intensity coding in fibromyalgia patients and controls [abstract]. Arthritis Rheum 2001;44 Suppl 9:S394.

10. Vaeroy H, Helle R, Foore O, Kass E, Terenius L. Elevated CSF levels of substance $\mathrm{P}$ and high incidence of Raynaud phenomenon in patients with fibromyalgia: new features for diagnosis. Pain 1988;32:21-6.

11. Russell IJ, Orr MD, Littman B, Vipraio GA, Alboukrek D,
Michalek JE, et al. Elevated cerebrospinal fluid levels of substance $\mathrm{P}$ in patients with the fibromyalgia syndrome. Arthritis Rheum 1994;37:1593-601.

12. Welin M, Bragee B, Nyberg F, Kristiansson M. Elevated substance $\mathrm{P}$ levels are contrasted by a decrease in met-enkephalin-arg-phe levels in CSF from fibromyalgia patients [abstract]. J Musculoskeletal Pain 1995;3:4.

13. Bradley LA, Alberts KR, Alarcon GS, Alexander MT, Mountz JM, Wiegent DA, et al. Abnormal brain regional cerebral blood flow (rCBF) and cerebrospinal fluid (CSF) levels of substance P (SP) in patients and non-patients with fibromyalgia (FM) [abstract]. Arthritis Rheum 1996;39 Suppl 9:S212.

14. Crofford LJ, Pillemer SR, Kalogeras KT, Cash JM, Michelson D, Kling MA, et al. Hypothalamic-pituitary-adrenal axis perturbations in patients with fibromyalgia. Arthritis Rheum 1994;37: 1583-92.

15. Griep EN, Boersma JW, de Kloet EP. Altered reactivity of the hypothalamic-pituitary-adrenal axis in the primary fibromyalgia syndrome. J Rheumatol 1993;20:469-74.

16. Griep EN, Boersma JW, Lentjes EG, Prins AP, ven der Korst JK, de Kloet ER. Function of the hypothalamic-pituitary-adrenal axis in patients with fibromyalgia and low back pain. J Rheumatol 1998;25:1374-81.

17. Neeck G, Crofford LJ. Neuroendocrine perturbations in fibromyalgia and chronic fatigue syndrome. Rheum Dis Clin North Am 2000;26:989-1002.

18. Martinez-Lavin M, Hermosillo AG, Mendoza C, Ortiz R, Cajigas JC, Pineda C, et al. Orthostatic sympathetic derangement in subjects with fibromyalgia. J Rheumatol 1997;24:714-8.

19. Martinez-Lavin M, Hermosillo AG, Rosas M, Soto ME. Circadian studies of autonomic nervous balance in patients with fibromyalgia: a heart rate variability analysis. Arthritis Rheum 1998;41: 1966-71.

20. Kelemen J, Lang E, Balint G, Trocsanyi M, Muller W. Orthostatic sympathetic derangement of baroreflex in patients with fibromyalgia. J Rheumatol 1998;25:823-5.

21. Petzke F, Clauw DJ. Sympathetic nervous system function in fibromyalgia. Curr Rheumatol Rep 2000;2:116-23.

22. Cohen H, Neumann L, Alhosshle A, Kotler M, Abu-Shakra M, Buskila D. Abnormal sympathovagal balance in men with fibromyalgia. J Rheumatol 2001;28:581-9.

23. Bennett RM, Cook DM, Clark SR, Burckhardt CS, Campbell SM. Hypothalamic-pituitary-insulin-like growth factor-I axis dysfunction in patients with fibromyalgia. J Rheumatol 1997;24:1384-9.

24. Bennett RM, Clark SC, Walczyk J. A randomized, double-blind, placebo-controlled study of growth hormone in the treatment of fibromyalgia. Am J Med 1998;104:227-31.

25. Hawley DJ, Wolfe F. Pain, disability, and pain/disability relationships in seven rheumatic disorders: a study of 1,522 patients. J Rheumatol 1991;18:1552-7.

26. Callahan LF, Smith WJ, Pincus T. Self-report questionnaires in five rheumatic diseases: comparisons of health status constructs and associations with formal education level. Arthritis Care Res 1989;2:122-31.

27. Wolfe F, Skevington SM. Measuring the epidemiology of distress: the rheumatology distress index. J Rheumatol 2000;27:2000-9.

28. Clauw DJ, Chrousos GP. Chronic pain and fatigue syndromes: overlapping clinical and neuroendocrine features and potential pathogenic mechanisms. Neuroimmunomodulation 1997;4:134-53.

29. Clauw DJ, Paul P. The overlap between fibromyalgia and inflammatory rheumatic diseases: when and why does it occur? J Clin Rheumatol 1995;1:335-41. 